\title{
CLOUD COMPUTING MIGRATION BARRIERS AND ADVANTAGES IN MANUFACTURING - AN ANALYSIS OF AMBIGUITY AND DEPENDENCES IN THE ASSESSMENT CRITERIA
}

\section{Witold Bartkiewicz}

University of Lodz, Lodz, Poland

e-mail: wbartkiewicz@wzmail.uni.lodz.pl

ORCID: 0000-0002-1846-9056

\section{Zbigniew Gontar}

Warsaw School of Economics, Warsaw, Poland e-mail: zbigniew.gontar@sgh.waw.pl

ORCID: 0000-0001-9870-0141

(C) 2018 Witold Bartkiewicz, Zbigniew Gontar

This is an open access article distributed under the Creative Commons Attribution-NonCommercial-NoDerivs license (http://creativecommons.org/licenses/by-nc-nd/3.0/)

DOI: 10.15611/eada.2018.3.03

JEL Classification: C3, C38

\begin{abstract}
There is still many misunderstandings associated with the assessment of the barriers encountered in the process of IT solutions migration to the computational cloud and the benefits to be expected. The purpose of this paper is to organize the criteria used in this field, to analyze the dependencies between them. This will allow us to better understand the problem of migration to the cloud and to improve the decision-making processes related to it. A comprehensive survey was carried out, covering about 400 manufacturing enterprises in Poland using cloud-based IT solutions in various areas. The elements of the study were questions about the barriers and benefits encountered in this process. The paper analyzes the relationships between the obtained categories using diverse data mining methods: association rules mining and hierarchical agglomerative clustering. The obtained results allow to identify the conceptual structure and build a model of relationships inside the problem.
\end{abstract}

Keywords: cloud computing; association mining, similarity based semantic clustering.

\section{Introduction}

Among several ICT's efforts to promote the development of the manufacturing industry, cloud computing application to the manufacturing industry in general and cloud manufacturing (CMfg) in particular, are viewed as important issues [Liu, $\mathrm{Xu}$ 2016]. Identifying the barriers and benefits of cloud computing migration in 
manufacturing and their analysis provides a structured view of the obstacles and opportunities in the way of manufacturing development, and their grouping in a new taxonomy scheme to understand - through new categories at a higher level of generality - the reasons for moving to a new area of manufacturing, and to give empirical guidance as to how to apply cloud computing in manufacturing practice.

Although some general benefits and barriers of the adoption of cloud services are known, the understanding of this domain is still unsatisfactory. The pros and cons influencing the decisions in this area are numerous, complex, overlapping and heterogenic. Some of them are created by the distributed nature of the computing cloud, in a positive (e.g. easy access to ICT services) and negative (e.g. security issues) meaning. Others have their origin in the fact that migration to the cloud is essentially an outsourcing decision (reduced costs and concentration on the business's core vs. reliance on an external entity - the cloud service provider). Further sources of the advantages and barriers in migration to the computational cloud include personal factors (human routine and fears, competences), environmental, technological, organizational, and many others [Lian et al. 2014].

For this reason, the issue of the identification of cloud migration advantages and the barriers and relationships between them, has aroused great interest in recent years. However, the used approaches were focused mainly on qualitative expertbased methods. For instance El-Gazzar, Hustad and Olsen used the Delphi study approach [El-Gazzar et al. 2016], Schneider et al. adopted the expert-based taxonomy creation method [Schneider et al. 2014]. Empirical studies are usually limited to the utilization of descriptive statistics [Lian et al. 2014] and deductive methods based on econometrical modelling (logit models) for verifying the hypotheses regarding the assumed relationships [Low et al. 2011]. A good review of those approaches can be found in [Schneider, Sunyaev 2016]. Some recent developments take advantage of using more complex modelling schemes based on neural networks [Ooi et al. 2018], but also in the supervised learning framework of assumed relationships.

In our study we followed another way of thinking. To determine the structure of the advantages and barriers in cloud adoption we applied a purely inductive self-organized approach based on association mining for detecting associative relationships between the selected factors, and hierarchical clustering for detecting hierarchical, taxonomical dependences. That allowed us to find and confirm the relationships between the benefits and barriers in cloud adoption without any a priori knowledge about the problem, based solely on the information originated from experienced managers responsible for implementing cloud solutions in their companies. 


\section{Adoption of cloud computing services - advantages and barriers}

To identify the strengths, weaknesses, opportunities and threats for migration to the cloud in the manufacturing industry, and to specify a set of recommendations for the practitioners [Marston et al. 2011], we performed an empirical study of this topic, questioning IT managers from 400 manufacturing enterprises in Poland which implemented solutions based on the computational cloud.

As part of a more comprehensive research related to the subject of the adoption of cloud computing services, and the managerial changes resulting from this choice, we asked about the perceived benefits and barriers of this process.

Table 1. Migration to the cloud - list of advantages used in the study and the number of their occurrences in the respondents' selections

\begin{tabular}{|c|c|}
\hline Advantages & $\begin{array}{c}\text { No } \\
\text { of occurrences }\end{array}$ \\
\hline 1. Lower operational costs (associated with manufacturing) & 154 \\
\hline 2. Better adaptation to customers' and business partners' expectations & 164 \\
\hline 3. Better data utilization for knowledge management & 187 \\
\hline 4. New product development and creation of innovative solutions & 107 \\
\hline 5. New business models development & 88 \\
\hline 6. Better communication with business environment & 258 \\
\hline 7. Increased work efficiency & 211 \\
\hline 8. Reducing product time-to-market & 85 \\
\hline 9. Greater flexibility in offered products and services & 103 \\
\hline 10. Allows one to use computer software so far unavailable due to the high cost & 145 \\
\hline 11. More efficient allocation of resources & 162 \\
\hline 12. Improved manufacturing preparation & 100 \\
\hline 13. Improved manufacturing processes & 98 \\
\hline 14. Improved quality management processes & 107 \\
\hline 15. Fast access to knowledge & 208 \\
\hline 16. Access to specific production-relevant data & 127 \\
\hline 17. Faster and more efficient data processing & 259 \\
\hline 18. Easy access to data and applications from anywhere & 341 \\
\hline 19. Replacement of several applications with one environment & 167 \\
\hline 20. Guaranteed security (of the data and systems) & 180 \\
\hline 21. Ensuring better continuity of IT systems functioning & 219 \\
\hline 22. Fast access to newly introduced ICT technologies & 169 \\
\hline 23. More efficient application update & 198 \\
\hline 24. Reduced problems with infrastructure maintenance & 212 \\
\hline $\begin{array}{l}\text { 25. Increased ability to match computer systems functionality to business } \\
\text { processes }\end{array}$ & 146 \\
\hline
\end{tabular}

Source: own study. 
Table 2. Migration to the cloud - list of barriers used in the study and the number of their occurrences in the respondents' selections

\begin{tabular}{|l|c|}
\hline \multicolumn{1}{|c|}{ Barriers } & $\begin{array}{c}\text { No of } \\
\text { occurrences }\end{array}$ \\
\hline 1. Issues related to the protection of personal data & 235 \\
2. Legal aspects & 133 \\
3. Limited trust in new technologies & 108 \\
4. Concerns about the data and services' security & 242 \\
5. Fear of the cloud service providers' activities & 161 \\
6. Implementation costs & 81 \\
7. Difficulties with integration of solutions & 110 \\
8. Concerns about the quality of services provided by the cloud providers & 117 \\
9. Difficult access due to slow connection & 141 \\
10. Lack of knowledge and competence & 112 \\
11. Unknown influence on company management & 45 \\
12. Complexity of SLA agreements & 80 \\
\hline
\end{tabular}

Source: own study.

The lists of advantages and barriers used in the study are shown in Table 1 and Table 2. Because there are no standards for this issue, the lists were developed on the basis of thorough research on the subject literature, and our expert knowledge. In the same way, the verification of the logical correctness of individual options, their completeness and non-overlapping character, was carried out. Certain questions may give rise to the suggestion of a homogeneous list of possible advantages and barriers of cloud migration in the case of different business profiles. However in this case it is possible because we are interested in issues related to the implementation of cloud solutions itself, and the strategic aspects of its impact on the management of the enterprise.

The respondents were supposed to choose all the perceived benefits and problems from both lists (multiple choice query). In the advantages analysis from the total number of 400 received responses, 10 questionnaires were rejected as containing none or all (chosen all 25 benefits categories) answers. In the case of barriers analysis the number of rejected responses was 22 .

Table 1 also contains the number of occurrences of each category in cloud adoption advantages in the choices of the respondents. As we can see, the frequency of individual categories is not equally distributed. The respondents paid the most attention to such benefits as easy access to data and computer systems from anywhere, faster and more efficient data processing, better communication with business environment, and ensuring better continuity of IT systems functioning. A relatively smaller importance was attributed to such advantages as reducing product time-tomarket, new business models development or improved manufacturing processes. This indicates that respondents were more interested in technical IT-related benefits than general business ones. 
The same issues were observed for barriers categories shown in Table 2. Also in this case there is significant inequality in the frequency of the distribution of individual concerns categories. Most often the responders chose barriers related to security as: concerns about the data and services' security, and issues related to the protection of personal data. Lesser importance was attributed to influence on company management, complexity of SLA agreements and fears about the cost of the adopted implementation of cloud services.

The frequency of occurrence of cloud migration advantages and barriers categories did not influence the strength of the discovered relationships presented in the next sections, because of the normalization of the similarity measures.

\section{Analysis of the internal relationships structure of the advantages and barriers in the cloud adoption problem}

\subsection{Identification of hierarchical relationships with similarity-based clustering}

Similarity-based methods for the identification of semantic relationships between conceptual categories make use of clustering algorithms applying measures of similarity between categories, based on the frequency of their co-occurrence in the choices made by individual respondents.

Let $n$ denotes the number of respondents, $m$ the number of categories used to indicate the benefits or barriers related to migration to the cloud. Let us denote by $\mathbf{X}[n \times m]$ selection matrix of each category by the responders, i.e. for each $i=1, \ldots$, $n, j=1, \ldots, m, x_{i j}=1$, if in the $i$-th questionnaire $j$-th category was indicated by the respondent, $x_{i j}=0$ otherwise.

The similarity (association) coefficient between the two categories is defined as the number of co-occurrences of these categories in individual questionnaires. Thus the similarity matrix $\mathbf{C}[m \times m]$ for the categories, is given:

$$
\mathbf{C}=\mathbf{X}^{T} \mathbf{X} \text {. }
$$

The $\mathbf{C}$ matrix is unnormalized, and usually the similarities are normalized in relation to the number of occurrences of each category separately in the respondents' answers. The normalized similarity matrix $\mathbf{S}[\mathrm{m} \times \mathrm{m}]$ may have the form:

$$
s_{i j}=\frac{c_{i j}}{c_{i i}+c_{j j}-c_{i j}},
$$

where $i, j=1, \ldots, m$.

In the case of our study, the benefits perceived by respondents from the transition to the computational cloud, the number of categories is 25 and the similarity matrix $\mathbf{S}$ has a dimension $25 \times 25$ and is shown in Figure 1. The individual rows and columns of that matrix correspond to the categories in Table 1. 
$\begin{array}{lllllllllllllllllllllllll}1 & 2 & 3 & 4 & 5 & 6 & 7 & 8 & 9 & 10 & 11 & 12 & 13 & 14 & 15 & 16 & 17 & 18 & 19 & 20 & 21 & 22 & 23 & 24 & 25\end{array}$

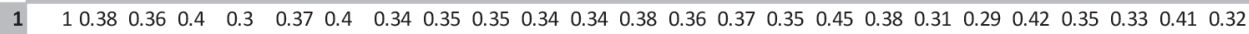
$\begin{array}{llllllllllllllllllllllllllllll}2 & 0.38 & 1 & 0.41 & 0.33 & 0.34 & 0.41 & 0.37 & 0.33 & 0.34 & 0.36 & 0.36 & 0.32 & 0.32 & 0.38 & 0.4 & 0.35 & 0.41 & 0.42 & 0.38 & 0.32 & 0.38 & 0.38 & 0.39 & 0.34 & 0.34\end{array}$

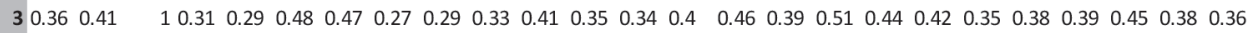
$\begin{array}{llllllllllllllllllllllllll}4 & 0.4 & 0.33 & 0.31 & 1 & 0.4 & 0.33 & 0.29 & 0.41 & 0.43 & 0.36 & 0.29 & 0.37 & 0.37 & 0.39 & 0.29 & 0.36 & 0.28 & 0.28 & 0.3 & 0.25 & 0.34 & 0.31 & 0.29 & 0.27 & 0.34\end{array}$

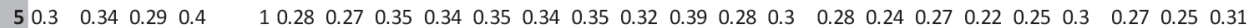

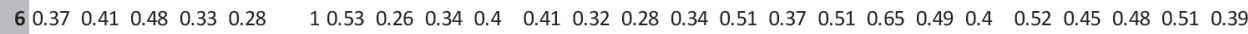

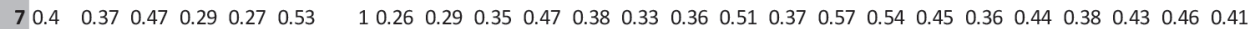

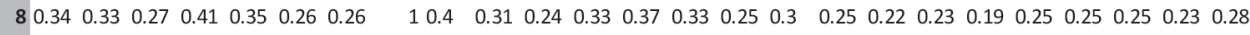
$\begin{array}{llllllllllllllllllllllllll}9 & 0.35 & 0.34 & 0.29 & 0.43 & 0.34 & 0.34 & 0.29 & 0.4 & 1 & 0.4 & 0.34 & 0.4 & 0.39 & 0.4 & 0.31 & 0.33 & 0.29 & 0.28 & 0.32 & 0.26 & 0.36 & 0.35 & 0.31 & 0.32 & 0.32\end{array}$

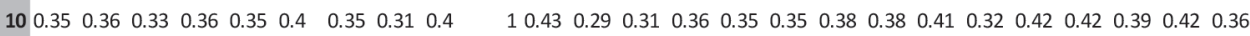
$\begin{array}{lllllllllllllllllllllllllllll}11 & 0.34 & 0.36 & 0.41 & 0.29 & 0.34 & 0.41 & 0.47 & 0.24 & 0.34 & 0.43 & 1 & 0.32 & 0.31 & 0.4 & 0.46 & 0.37 & 0.46 & 0.42 & 0.45 & 0.4 & 0.43 & 0.46 & 0.46 & 0.41 & 0.39\end{array}$ $\begin{array}{lllllllllllllllllllllllllll}12 & 0.34 & 0.32 & 0.35 & 0.37 & 0.35 & 0.32 & 0.38 & 0.33 & 0.4 & 0.29 & 0.32 & 1 & 0.6 & 0.57 & 0.36 & 0.47 & 0.32 & 0.26 & 0.28 & 0.23 & 0.26 & 0.32 & 0.31 & 0.24 & 0.37\end{array}$ $\begin{array}{lllllllllllllllllllllllllll}13 & 0.38 & 0.32 & 0.34 & 0.37 & 0.32 & 0.28 & 0.33 & 0.37 & 0.39 & 0.31 & 0.31 & 0.6 & 1 & 0.6 & 0.38 & 0.43 & 0.31 & 0.26 & 0.3 & 0.24 & 0.26 & 0.31 & 0.32 & 0.24 & 0.33\end{array}$

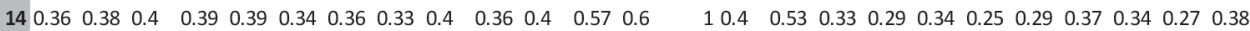
$\begin{array}{llllllllllllllllllllllllll}15 & 0.37 & 0.4 & 0.46 & 0.29 & 0.28 & 0.51 & 0.51 & 0.25 & 0.31 & 0.35 & 0.46 & 0.36 & 0.38 & 0.4 & 1 & 0.39 & 0.54 & 0.53 & 0.42 & 0.35 & 0.46 & 0.41 & 0.52 & 0.44 & 0.4\end{array}$ $\begin{array}{llllllllllllllllllllllllll}16 & 0.35 & 0.35 & 0.39 & 0.36 & 0.3 & 0.37 & 0.37 & 0.3 & 0.33 & 0.35 & 0.37 & 0.47 & 0.43 & 0.53 & 0.39 & 1 & 0.36 & 0.33 & 0.32 & 0.26 & 0.33 & 0.38 & 0.38 & 0.32 & 0.39\end{array}$

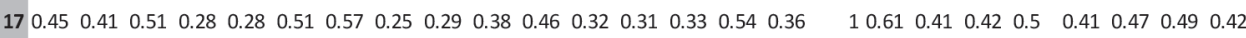
$\begin{array}{lllllllllllllllllllllllllllll}18 & 0.38 & 0.42 & 0.44 & 0.28 & 0.24 & 0.65 & 0.54 & 0.22 & 0.28 & 0.38 & 0.42 & 0.26 & 0.26 & 0.29 & 0.53 & 0.33 & 0.61 & 1 & 0.42 & 0.46 & 0.57 & 0.45 & 0.51 & 0.54 & 0.4\end{array}$

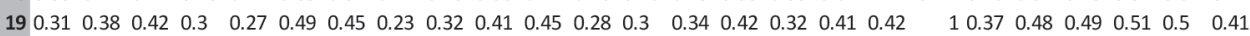
$\begin{array}{llllllllllllllllllllllllllll}20 & 0.29 & 0.32 & 0.35 & 0.25 & 0.22 & 0.4 & 0.36 & 0.19 & 0.26 & 0.32 & 0.4 & 0.23 & 0.24 & 0.25 & 0.35 & 0.26 & 0.42 & 0.46 & 0.37 & 1 & 0.44 & 0.38 & 0.41 & 0.42 & 0.3\end{array}$

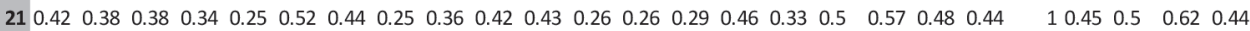
$\begin{array}{llllllllllllllllllllllllllll}22 & 0.35 & 0.38 & 0.39 & 0.31 & 0.3 & 0.45 & 0.38 & 0.25 & 0.35 & 0.42 & 0.46 & 0.32 & 0.31 & 0.37 & 0.41 & 0.38 & 0.41 & 0.45 & 0.49 & 0.38 & 0.45 & 1 & 0.55 & 0.46 & 0.45\end{array}$

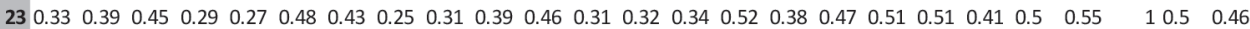
$\begin{array}{llllllllllllllllllllllllll}24 & 0.41 & 0.34 & 0.38 & 0.27 & 0.25 & 0.51 & 0.46 & 0.23 & 0.32 & 0.42 & 0.41 & 0.24 & 0.24 & 0.27 & 0.44 & 0.32 & 0.49 & 0.54 & 0.5 & 0.42 & 0.62 & 0.46 & 0.5 & 1 & 0.37\end{array}$ $\begin{array}{llllllllllllllllllllllllll}25 & 0.32 & 0.34 & 0.36 & 0.34 & 0.31 & 0.39 & 0.41 & 0.28 & 0.32 & 0.36 & 0.39 & 0.37 & 0.33 & 0.38 & 0.4 & 0.39 & 0.42 & 0.4 & 0.41 & 0.3 & 0.44 & 0.45 & 0.46 & 0.37 & 1\end{array}$

Fig. 1. A similarity matrix $\mathbf{S}$ for the benefits of migrating to a computational cloud

Source: own study.

\begin{tabular}{r|rrrrrrrrrrrrrr} 
& & 1 & 2 & 3 & 4 & 5 & 6 & 7 & 8 & 9 & 10 & 11 & 12 \\
$\mathbf{2}$ & 0.45 & 1 & 0.45 & 0.29 & 0.61 & 0.4 & 0.14 & 0.26 & 0.35 & 0.27 & 0.27 & 0.14 & 0.25 \\
3 & 0.29 & 0.22 & 1 & 0.22 & 0.33 & 0.3 & 0.17 & 0.19 & 0.3 & 0.22 & 0.22 & 0.21 & 0.27 \\
4 & 0.61 & 0.33 & 0.34 & 1 & 0.27 & 0.2 & 0.26 & 0.32 & 0.25 & 0.31 & 0.22 & 0.18 \\
5 & 0.4 & 0.3 & 0.27 & 0.43 & 1 & 0.17 & 0.26 & 0.32 & 0.28 & 0.3 & 0.17 & 0.27 \\
6 & 0.14 & 0.17 & 0.2 & 0.17 & 0.19 & 1 & 0.31 & 0.43 & 0.33 & 0.21 & 0.17 & 0.24 \\
7 & 0.26 & 0.19 & 0.26 & 0.26 & 0.31 & 0.22 & 1 & 0.15 & 0.17 & 0.27 & 0.17 & 0.15 \\
8 & 0.35 & 0.3 & 0.32 & 0.32 & 0.43 & 0.15 & 0.33 & 1 & 0.24 & 0.3 & 0.19 & 0.19 \\
9 & 0.27 & 0.22 & 0.25 & 0.28 & 0.33 & 0.17 & 0.24 & 0.32 & 1 & 0.29 & 0.2 & 0.3 \\
10 & 0.27 & 0.22 & 0.31 & 0.3 & 0.21 & 0.27 & 0.3 & 0.29 & 0.29 & 1 & 0.11 & 0.2 \\
11 & 0.14 & 0.21 & 0.22 & 0.17 & 0.17 & 0.17 & 0.19 & 0.2 & 0.11 & 0.23 & 1 & 0.34 \\
12 & 0.25 & 0.27 & 0.18 & 0.27 & 0.24 & 0.15 & 0.19 & 0.3 & 0.2 & 0.34 & 0.32 & 1
\end{tabular}

Fig. 2. A similarity matrix $\mathbf{S}$ for the barriers of migrating to a computational cloud

Source: own study.

Similarly, in the case of barriers perceived for the transition to a computational cloud, based on the analysis of the indicated responses we received a similarity matrix $\mathbf{S}$ with dimensions of $12 \times 12$, as shown in Figure 2 . The rows and columns of this matrix correspond to the barriers in Table 2 .

In the next step, to identify vertical relations (in the sense of semantic generality) between the categories in the sets of benefits and barriers, we applied hierarchical 
agglomerative clustering. As a measure of the association between the categories, were adopted similarities, presented in the matrix in Figure 1 for the benefits, and in the matrix in Figure 2 for the barriers. In the clustering algorithm we also used a complete link method, i.e. the similarity between the two clusters was determined by the least similar elements.

Further, in the study the standard classical hierarchical agglomerative clustering algorithm was applied. The set of clustered objects is relatively small so there is no need to use the improved approaches such as the Ward method.

Table 3. The obtained clusters of the benefits from migration to the cloud at selected hierarchy levels

\begin{tabular}{|c|l|}
\hline Similarity & \multicolumn{1}{|c|}{ Clusters } \\
\hline 0.57 & $\{6,18\},\{7,17\},\{13,14\},\{21,24\}$ \\
\hline 0.51 & $\{6,15,18\},\{7,17\},\{12,13,14\},\{21,24\},\{22,23\}$ \\
\hline 0.45 & $\{6,7,15,17,18\},\{12,13,14\},\{19,21,22,23,24\}$ \\
\hline 0.40 & $\{3,6,7,15,17,18\},\{4,8,9\},\{10,11\},\{12,13,14,16\},\{19,21,22,23,24\}$ \\
\hline 0.36 & $\{1,2\},\{3,6,7,15,17,18,25\},\{4,8,9\},\{12,13,14,16\},\{10,11,19,21,22,23,24\}$ \\
\hline 0.32 & $\{1,2,12,13,14,16\},\{3,6,7,10,11,15,17,18,19,21,22,23,24,25\},\{4,5,8,9\}$ \\
\hline
\end{tabular}

Source: own study.

Table 3 presents the results of clustering at the most important levels for the advantages from migration to the cloud. We refrained from the presentation of the full dendrogram of created clusters, focusing only on its elements, most important for identifying hierarchical relationships between categories. At each level we show only the formed clusters of category groups. Other categories not listed in the table form one-element clusters.

As we can see, at the highest levels of similarity there are created four clusters: $\{6,18\}$ - advantages concerning the improvement of communication functions and information exchange in the enterprise, $\{7,17\}$ - increasing efficiency of the enterprise, $\{13,14\}$ - improving the quality and efficiency of production and $\{21$, $24\}$ - increasing the efficiency of information systems.

At the next level the clusters expand, adding new benefits in line with their semantics $(\{6,15,18\}$ and $\{12,13,14\})$. There is also a new group of benefits $-\{22$, $23\}$, related to facilitating the development and maintenance of information systems infrastructure.

Next (the third row in Table 5) we can see that the advantages related to communication functions and information exchange and the effectiveness of the company's operation are combined into one group $(\{6,7,15,17,18\})$, which can be defined as the benefits of raising company's efficiency. Similar factors are connected with the advantages in the functioning of the information technology infrastructure $\{19,21,22,23,24\}$. 
The next level shows clearly defined thematic clusters of advantages: $\{4,8,9\}-$ related to the facilitation of creating new and improving existing company's products and services, and $\{10,11\}$ - access to new computer software and other resources of the enterprise.

At the next level, the latter group combines with other benefits related to IT infrastructure, creating a cluster $\{10,11,19,21,22,23,24\}$, and shows a new group of advantages $\{1,2\}$ that combines the benefits related to the production and distribution of the company's products.

Table 4. The obtained clusters of the barriers in migration to the cloud at selected hierarchy levels

\begin{tabular}{|c|l|}
\hline Similarity & \multicolumn{1}{|c|}{ Clusters } \\
\hline 0.34 & $\{1,4\},\{5,8\},\{10,12\}$ \\
\hline 0.26 & $\{1,2,4\},\{3,7\},\{5,8,9\},\{10,12\}$ \\
\hline 0.23 & $\{1,2,4\},\{3,5,7,8,9\},\{6\},\{10,11,12\}$ \\
\hline
\end{tabular}

Source: own study.

At the last level, the advantages are organized into three large, quite unambiguously interpretable clusters: $\{1,2,12,13,14,16\}$ - benefits related to improving the production and sale of products and services of the company, $\{4,5,8,9\}$ - related to the creation of new, better products on the market, and $\{3,6,7,10,11,15,17,18$, $19,21,22,23,24,25\}$ - regarding the operation of the company itself, improvements regarding the production efficiency, access to resources, supporting systems, etc.

Similarly, the results of the hierarchical clustering of barriers in migration to cloud computing are presented in Table 4. As in the case of benefits, we focus only on the most important levels of cluster hierarchy.

The first clusters were consisted of barriers: $\{1,4\}$ - concerns about the security of data and services, especially personal data, $\{5,8\}$ - related to cloud service providers, and $\{10,12\}$ - lack of full knowledge and understanding about the technical and commercial functioning conditions in the computing cloud.

At a further level, the cluster of barriers related to security $\{1,2,4\}$, has been extended to include concerns regarding the legal aspects, creating a more general group of barriers related to the technical and legal security of data and services. Similarly, the set of barriers related to the cloud service provider $\{5,8,9\}$ has been expanded for another factor. We can talk about a wider group of concerns about the quality of cloud solutions. A new group of barriers $\{3,7\}$ emerged, related to concerns about the use of new information and telecommunications technologies in the enterprise and the need for the adaptation of the currently used solutions. At the higher level, both previous mentioned clusters will be connected.

Finally, we can see that the barriers in migration to the cloud can be divided into four basic groups: $\{1,2,4\}$ - related to technical and legal security of data and services in the cloud; $\{3,5,7,8,9\}$ - technical barriers, related to concerns 
about the quality of cloud providers' services and the functioning of advanced new technologies and the ability to adapt their own solutions; $\{6\}$ - concerns about the costs of migration to the cloud; and $\{10,11,12\}$ - lack of know-how and competence in terms of the operation with new IT solutions and technical-commercial conditions in the cloud.

\subsection{Identification of associative relationships based on association rules mining}

The methods of identifying semantic relations between conceptual categories based on associations are also used in issues related to binary association rules. Associative clustering with use of binary association rules is also a two-step procedure. In the first step, one must specify association rules between categories, i.e. decide which category implies which other category.

Association analysis in the sense of binary association rules has its roots in Rakesh Agrawal et al. publication from 1993 [Agrawal et al. 1993], and is aimed at finding association rules in a given database as the following implication: $X \Rightarrow Y, X \cap Y=0$, where $\mathrm{X}$ and $\mathrm{Y}$ are sets of binary attributes called items. A database is a set of transactions, where each transaction has a unique transaction ID and contains a subset of the items. In our case, the transaction refers to the respondent's survey responses, and the items refer to the conceptual category of the pros and cons of cloud manufacturing. The rules are created on the basis of various measures of significance and interest, including support and confidence. The support of itemset $X$ is defined as the proportion of transactions in the data set which contain the itemset. The confidence of a rule is defined as follows: $\operatorname{conf}(X \Rightarrow Y)=\operatorname{supp}(X \cup Y) / \operatorname{supp}(X)$, and can be interpreted as an estimate of the conditional probability $\mathrm{P}(\mathrm{Y} \mid \mathrm{X})$.

Since binary association rules require defining support and confidence between multiple categories as the number of co-occurrence of these categories in individual surveys, similarity matrix $\mathbf{C}[m \times m]$ is replaced by a multidimensional cube. Due to the computational complexity of these measures' generation in a multidimensional environment, a Microsoft SQL Server tool was used for building binary association rules. Therefore association analysis in the sense of binary association rules means the identification of associations between objects on the basis of object-values data table, expressed in the form of association rules (if-then statements), and supportconfidence framework. The best known association rules algorithm is the a priori algorithm, referring to the two step approach, i.e. finding frequent itemsets (large itemsets) which meet or exceed the minimum support, and using these itemsets to generate association rules. In general, for given $d$ unique items the total number of possible association rules is given by the following value:

$$
R=\sum_{k=1}^{d-1}\left[\left(\begin{array}{l}
d \\
k
\end{array}\right) \times \sum_{j=1}^{d-k}\left(\begin{array}{c}
d-k \\
j
\end{array}\right)\right] .
$$


In the case of the analysis of the benefits of migration to the cloud, we assumed for the categories that are in relation to each other, the threshold of MINIMUM PROBABILITY as 0.5 and MINIMUM_SUPPORT as 0.3. The resulting set of associative rules representing associations between benefit categories is presented in Table 5. Detailed considerations concerning Probability, Importance, MINIMUM PROBABILITY, and MINIMUM_SUPPORT are given in the Microsoft Association Algorithm Technical Reference [Microsoft 2012].

Table 5. Binary association rules related to the benefits of migration to the cloud

\begin{tabular}{|c|c|c|}
\hline Probability & Importance & Rule \\
\hline 0.983 & 0.093 & $22,21->18$ \\
\hline 0.977 & 0.092 & $22,23->18$ \\
\hline 0.977 & 0.091 & $15,24->18$ \\
\hline 0.970 & 0.088 & $7,21->18$ \\
\hline 0.970 & 0.087 & $22,6->18$ \\
\hline 0.969 & 0.085 & $24,21,17->18$ \\
\hline 0.967 & 0.082 & $21,17,6->18$ \\
\hline 0.893 & 0.248 & $19,18->6$ \\
\hline 0.886 & 0.227 & $15,7->17$ \\
\hline 0.873 & 0.209 & $7,24->17$ \\
\hline 0.867 & 0.204 & $15,21->17$ \\
\hline 0.848 & 0.350 & $24,6,18->21$ \\
\hline 0.844 & 0.336 & $24,17,18->21$ \\
\hline 0.838 & 0.211 & $19->6$ \\
\hline 0.838 & 0.196 & $1->17$ \\
\hline 0.836 & 0.354 & $24,6->21$ \\
\hline 0.836 & 0.180 & $15,7->6$ \\
\hline 0.833 & 0.181 & $3,6->17$ \\
\hline 0.831 & 0.189 & $24,21,18->6$ \\
\hline 0.826 & 0.178 & $11,18->17$ \\
\hline 0.821 & 0.186 & $11->17$ \\
\hline 0.821 & 0.327 & $24,17->21$ \\
\hline 0.819 & 0.182 & $3,18->6$ \\
\hline 0.819 & 0.182 & $3,18->17$ \\
\hline
\end{tabular}

Source: own study.

Table 6. Clusters of the benefits of migration to the cloud

\begin{tabular}{|c|}
\hline Clusters \\
\hline$\{21,24\},\{22,23\},\{1,17\},\{7,11\}$ \\
\hline
\end{tabular}

Source: own study. 
As we can see in the case of benefits in migration to cloud computing, some of the categories were indicated by the respondents as independent. These included categories 10 and 25 .

The second step - as in the case of creating associative clusters based on the similarity matrix $\mathbf{S}$ - consists in defining the clusters themselves, i.e. determining which categories are part of the same cluster. Here too, the dependencies between categories can be inconsistent. To generate consistent clusters of categories we used the algorithm for searching for complete graphs included in the Microsoft SQL Server tool. The group of categories obtained as a result of our analysis defining the benefits related to the transition to the cloud, are shown in Table 6 .

Table 7. Binary association rules related to the barriers of migration to the cloud

\begin{tabular}{|c|c|c|}
\hline Probability & Importance & Rule \\
\hline 0.937 & 0.28623 & $2,4->1$ \\
\hline 0.886 & 0.240191 & $8,4->1$ \\
\hline 0.885 & 0.244654 & $5,1->4$ \\
\hline 0.857 & 0.273118 & $2->1$ \\
\hline 0.839 & 0.187723 & $8,1->4$ \\
\hline 0.833 & 0.233443 & $5,4->1$ \\
\hline 0.815 & 0.181188 & $3->4$ \\
\hline 0.795 & 0.195498 & $8->1$ \\
\hline 0.781 & 0.156647 & $2,1->4$ \\
\hline 0.772 & 0.305853 & $1->4$ \\
\hline 0.752 & 0.133196 & $8->4$ \\
\hline 0.75 & 0.161553 & $5->4$ \\
\hline 0.746 & 0.329395 & $4->1$ \\
\hline 0.739 & 0.117921 & $10->4$ \\
\hline 0.722 & 0.123785 & $3->1$ \\
\hline 0.718 & 0.411426 & $8->5$ \\
\hline 0.714 & 0.105886 & $2->4$ \\
\hline 0.706 & 0.139276 & $5->1$ \\
\hline 0.603 & $\sim 0$ & $9->4$ \\
\hline 0.582 & $\sim 0$ & $9->1$ \\
\hline 0.559 & 0.295767 & $1,4->5$ \\
\hline 0.525 & 0.559493 & $5->8$ \\
\hline 0.5 & 0.276518 & $4->5$ \\
\hline
\end{tabular}

Source: own study. 
Table 8. Clusters of the barriers of migration to the cloud

\begin{tabular}{|c|}
\hline Clusters \\
\hline$\{5,8\},\{1,4\}$ \\
\hline
\end{tabular}

Source: own study.

The categories $\{21,24\},\{22,23\}$ are related to the IT management in the enterprise, including ensuring better continuity of IT systems operations, fast access to newly released ICT technologies, more efficient application update, reduced problems with infrastructure maintenance, creating a group of benefits related to this field, and indicating that the respondents connect issues related to manufacturing infrastructure. This indicates a desire to seek IT solutions that support innovation in manufacturing.

The categories $\{1,17\}$ and $\{7,11\}$ indicate that respondents also combine issues related to operational efficiency and effectiveness in manufacturing operations in the sense of lower operational costs (associated with manufacturing), increased work efficiency, more efficient allocation of resources, and faster and more efficient data processing.

We conducted a similar analysis for barriers in migration to cloud computing. Due to the smaller number of categories and the more frequently chosen responses by respondents about the lack of barriers, in this case for the categories remaining in relation, we assumed MINIMUM_SUPPORT as 0.3 . The set of association rules between barrier categories is presented in Table 7 .

In the case of barriers in migration to cloud computing, some of the categories were also indicated by the respondents as independent. These included categories 9 and 10 .

The categories $\{1,2\}$ address the concerns of respondents regarding legal issues, especially the protection of personal data, and the data and services' security. They can be described as a formal and legal area.

Another group of barriers $\{5,8\}$ is associated with fears about the functioning of cloud service providers in the sense of the right quality of services. This indicates the respondents' concerns about the negative impact of external factors on the manufacturing processes.

\section{Conclusions}

In the paper the problem of the advantages and barriers in adopting cloud computing services in manufacturing enterprises was discussed. The obtained results allowed to identify the conceptual structure of the subject and build a model of associative and hierarchical relationships inside the barriers and benefits sets.

The hierarchical clustering procedure in Chapter 3.1 created consistent, easy to interpret taxonomy, allowing the identification of hierarchical dependences on 
various levels of semantical generality. As was shown in the discussion of the results presented in Tables 3 and 4, respectively, the respondents perceived the discussed advantages and barriers in the cloud migration problem, as closely topically related, in agreement with common knowledge. The presented analysis shows how the managers responsible for cloud migration projects associate the benefits and barriers on various levels of generality, and create more abstract and general concepts in view of the domain. This is an important issue for the development of the model of the advantages and barriers for cloud adoption tasks in enterprises.

Similarly the associative relationships resulted from the analysis in Chapter 3.2 are clearly explainable on a theoretical basis and show interesting dependences for decision making procedures in this field. The results presented in Table 6 and Table 8 , and the discussion that goes with them, show another important topic of the problem - they describe not hierarchical, but associative, cross-referential dependences between the concepts of the hierarchy of the advantages and barriers in the cloud migration problem. The discovery such hidden, non-observable connections equally important for its creation is mentioned in the model in the previous paragraph.

The advantage of our approach is the inductive nature of the dependencies obtained, independent of the simplified theoretical models of computational cloud adoption, widely used in the literature. It gives a deeper insight into the problem, making the obtained results independent of certain preconceived assumptions made in the expert knowledge-based approach. This also brings us closer to the current trends in data-driven management.

Knowing that cloud computing is an example of the operationalization of new industrial strategies, i.e. Industry 4.0, and UN Sustainable Development Goals (SDGs), knowledge of the structure of benefits and barriers of the adoption of cloud services has an essential value for manufacturing enterprises, allowing for targeting initiatives focused on developing a new manufacturing environment dedicated to state-of-the-art manufacturing technologies.

Our study is focused on Polish manufacturing enterprises, and the obtained findings cannot be immediately generalized on manufacturing environments in other countries. However the discovered dependences in cloud solution adoption features may possess certain general features, because of the mentioned above universal global trends in manufacturing.

\section{Bibliography}

Agrawal R., Imieliński T., Swami A., 1993, Mining association rules between sets of items in large databases, Proceedings of the 1993 ACM SIGMOD international conference on Management of data-SIGMOD ‘93, p. 207.

El-Gazzar R., Hustad E., Olsen D.H., 2016, Understanding cloud computing adoption issues: A Delphi study approach, The Journal of Systems and Software, no. 118, pp. 64-84.

Kowalski G.J., Maybury M.T., 2002, Information Storage and Retrieval Systems, Kluwer. 
Lian J.-W., Yen D.C., Wang Y.-T., 2014, An Exploratory Study to Understand the Critical Factors Affecting the Decision to Adopt Cloud Computing in a Taiwan Hospital, Journal of Information Management, no. 34, pp. 28-36.

Liu Y., Xu X., 2016, Industry 4.0 and Cloud Manufacturing: A Comparative Analysis, Journal of Manufacturing Science and Engineering, vol. 139, issue 3.

Low C., Chen Y., Wu M., 2011, Understanding the Determinants of Cloud Adoption, Journal of Information Management, no. 111, pp. 1006-1023.

Marston S., Li Z., Bandyopadhyay S., Zhang J, Ghalsasi A., 2011, Cloud computing - the business perspective, Decision Support Systems, vol. 51, issue 1, pp. 176-189

Microsoft, 2012, Microsoft Association Algorithm Technical Reference, http://msdn.microsoft.com/en-us/library/cc280428.aspx. (12.04.2018).

Ooi K.-B., Lee V.-H., Tan G.W.-H., Hew T.-S., Hew J.-J, 2018, Cloud computing in manufacturing: The next industrial revolution in Malaysia?, Expert Systems With Applications, no. 93, pp. 376-394.

Schneider S., Lansing J., Gao F., Sunyaev A., 2014, A Taxonomic Perspective on Certification Schemes: development of a taxonomy for cloud service certification criteria, Proceedings of the 47th Hawaii International Conference on System Sciences, pp. 4998-5007.

Schneider S., Sunyaev A., 2016, Determinant factors of cloud-sourcing decisions: reflecting on the IT outsourcing literature in the era of cloud computing, Journal of Information Technology, no. 31, pp. 1-31.

\section{BARIERY I KORZYŚCI MIGRACJI DO CHMURY OBLICZENIOWEJ W PRZEDSIĘBIORSTWACH PRZEMYSLOWYCH - ANALIZA NIEJEDNOZNACZNOŚCI I ZWIĄZKÓW MIĘDZY KRYTERIAMI OCENY}

Streszczenie: W artykule przeprowadzono analizę powiązań między korzyściami i barierami migracji systemów IT do chmury obliczeniowej w polskich przedsiębiorstwach produkcyjnych. Wykorzystano algorytm ,a priori”, pozwalający na eksplorację reguł asocjacyjnych, oraz metody semantycznego grupowania hierarchicznego opartego na podobieństwie. Otrzymane wyniki pozwalają zidentyfikować strukturę pojęciową zagadnienia oraz zbudować model zależności pomiędzy kryteriami oceny adopcji rozwiązań chmury obliczeniowej.

Słowa kluczowe: chmura obliczeniowa, eksploracja reguł asocjacyjnych, grupowanie semantyczne oparte na podobieństwie. 